\title{
Steel sheet coating paint film after pitting problems research
}

\author{
Jing $\mathrm{Xu}^{1, \mathrm{a}}$, JianWei Yang ${ }^{1, \mathrm{~b}}$, Jianqiang $\mathrm{ZHANG}^{1,2, \mathrm{c}}$, Fayun Zhang ${ }^{3, \mathrm{~d}}$, Jianping \\ $\mathrm{Cao}^{1, \mathrm{e}}$, Sheng Hai ${ }^{1, \mathrm{f}}$, Qian Zhao ${ }^{4, \mathrm{~g}}$ \\ ${ }^{1}$ Shougang research institute of technology, Beijing, 100043, China \\ ${ }^{2}$ China University of Petroleum, Beijing, 100043, China \\ ${ }^{3}$ Nuclear and Radiation Safety Center \\ ${ }^{4}$ China Shougang International Trade \& Engineering Corporation, Beijing, 100043, China \\ aemail: xujing1866@shougang.com.cn, bemail: jianwei_yang@163.com, cemail: zjq0943@126.com, \\ demail: brotherff@163.com, eemail: caojianping@shougang.com.cn, \\ femail: shenghai@shougang.com.cn, ${ }^{9}$ email: zhaoqian@zs.com.cn
}

Keywords: Auto-sheet, painting, dot corrosion, inclusion

Abstract. Use the labrotary methods to analysis the dot corrosion (DC) of steel sheet passivating film after the painting process. S-3400N type of SEM and EDS were employed to resarch the microstructure and the chemistcal component. The results showed the inclusion of sheet surface decrease the coverage and uniformity of passivating film, leading to the DC. One of the solve way is to control the mould caster to drease the inclusiong quantity and increase the quality of surface rolling sheet.

\section{Introduction}

Pipeline and automobile industry is one of the most important area of steel materials application today. With the innovation and development of the technology, good mechanical properties, such as problem solving, more steel mills and companies began to focus on the subsequent coating of -rolled automobile plate process adaptability and corrosion resistance. In order to ensure the quality of car plate paint, in car body need phosphating on automobile body before painting [1]. Phosphating technology is in the metal surface through the contact with the acidity phosphating liquid and in a series of chemical reactions that ultimately in the metal surface to form a layer of refractory, non-metallic, non-conductive, porous chemical conversion coating, the film is the phosphating film. Phosphating film can improve the adhesion and corrosion resistance of paint film [2]

\section{The result of the experiment and analysis}

\section{paint film pitting position analysis}

A steel plate after the coating treatment, local appeared in the process of salt spray test rust, bubbling and corrosion phenomenon, as shown in figure 1, it is not about car manufacturer of coating properties and corrosion resistance of the steel plate.

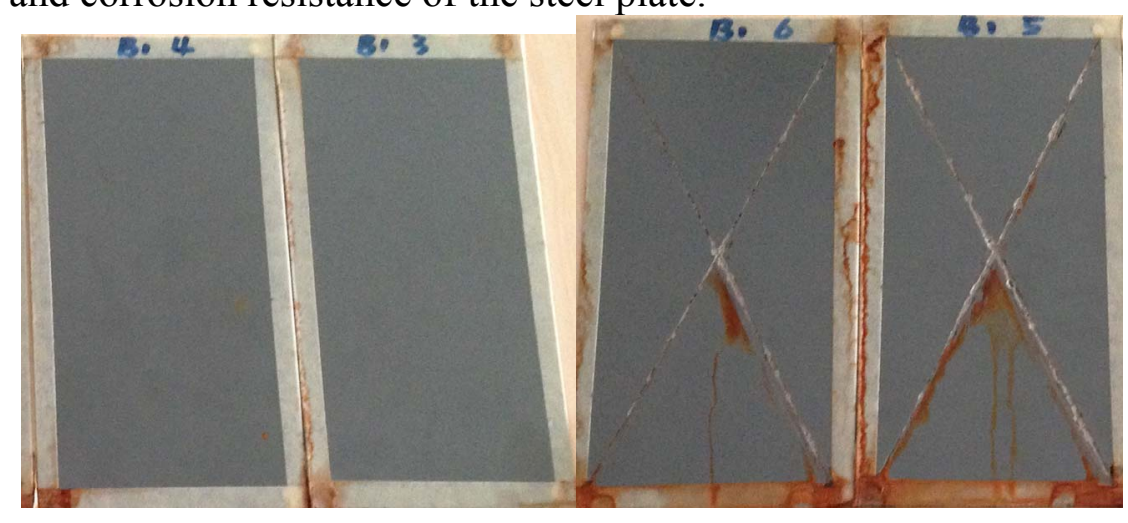

Fig1.Corrosion of coating-sample in salt spray test 
Using scanning electron microscope (SEM, EDX) of the paint film surface rust point location microscopic morphology observation and energy spectrum analysis. The results showed that the film rust point location was covered with a large number of corrosion products, mainly for iron oxide corrosion products. In addition, there are more of $\mathrm{Si}, \mathrm{Ca}, \mathrm{Al}, \mathrm{S}, \mathrm{Ti}$ and other elements. Considering the experiments, the phosphating liquid zinc - Mn - Ni ternary phosphating system, the phosphating liquid ingredient for phosphoric acid, zinc oxide and a small amount of manganese carbonate and nickel carbonate, it should contain the normal phosphating film in the $\mathrm{P}, \mathrm{O}, \mathrm{Mn}$, zinc, such as Fe, Ni elements. So presumably $\mathrm{Si}, \mathrm{Ca}, \mathrm{Al}, \mathrm{S}$, Ti elements such as the corrosion resistant properties of the phosphating film. The following not for salt fog test of phosphating film were analyzed, and try to locate corrosion at the characteristics of the phosphating film [3].

\section{phosphating film defects analysis}

Using scanning electronic microscope, SEM and EDX analysis of component of phosphating film as shown in figure 2 and table 1 . Normal position of the phosphating film containing $\mathrm{P}, \mathrm{O}, \mathrm{Mn}$, zinc, Fe element, consistent with the use of the phosphating liquid ingredients in our study, and in the phosphating film defect position basic does not contain $\mathrm{P}$, figure $2 \mathrm{a}$ to abnormal grain, $\mathrm{O}, \mathrm{Si}, \mathrm{Mn}$, Ti content on the high side, and there, $\mathrm{Al}, \mathrm{Ca}, \mathrm{Mg}$ and other elements, with the analysis before pitting in the film composition is similar, figure $2 \mathrm{~b}$ mainly for $\mathrm{Si}$ oxide; In the phosphating film defect position - leakage coating (Fig. 2c), only a small amount of $\mathrm{P}$ and O; Defect position (Fig. 2 d) - inclusions, the inclusions for $\mathrm{Al} 2 \mathrm{O} 3$, basic does not contain $\mathrm{P}$, at the defect that phosphating film defects will lead to leakage coating phosphating film.

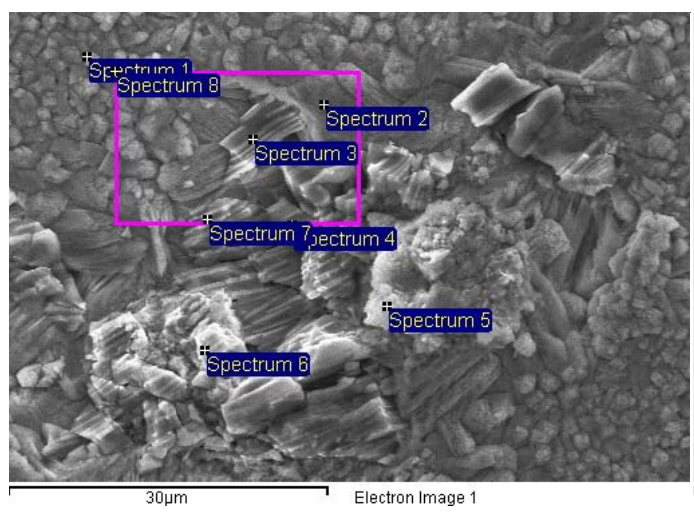

(a)

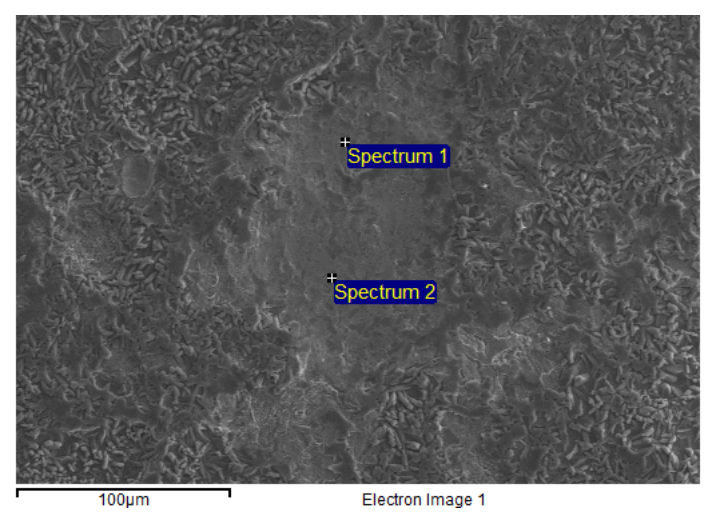

(c)

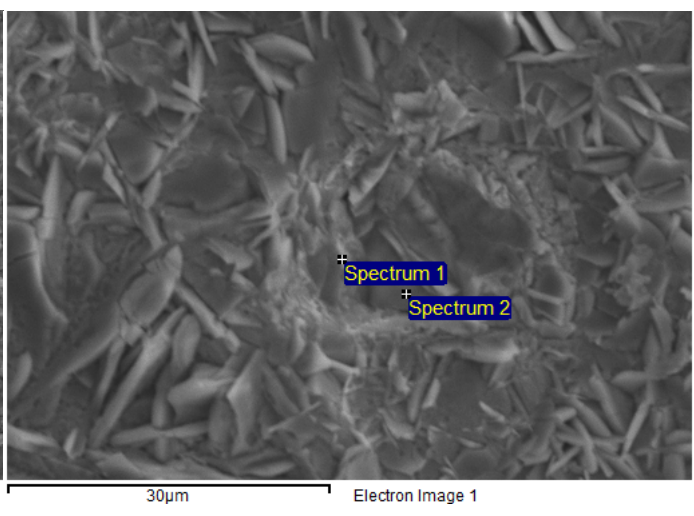

(b)

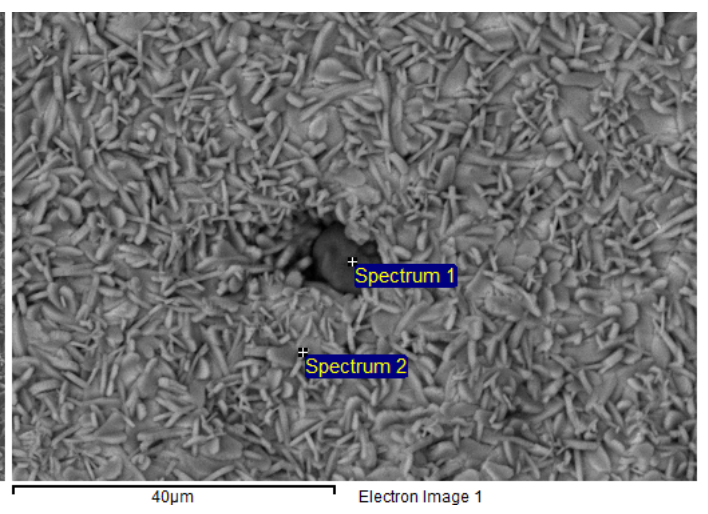

(d)

Fig2 defect SEM microscopic topography of phosphating film 
Table 1 EDS results of the phosphating film defect

\begin{tabular}{lllllllllllll}
\hline Fig.3 & $\mathrm{O}$ & $\mathrm{Na}$ & $\mathrm{Mg}$ & $\mathrm{Al}$ & $\mathrm{Si}$ & $\mathrm{P}$ & $\mathrm{K}$ & $\mathrm{Ca}$ & $\mathrm{Ti}$ & $\mathrm{Mn}$ & $\mathrm{Fe}$ & $\mathrm{Zn}$ \\
\hline (a) & 53.56 & 1.76 & 0.55 & 2.64 & 10.16 & & 2.52 & 2.89 & 13.23 & 6.07 & 6.61 & \\
(b) & 56.64 & & & & 41.57 & & & & & & & 1.79 \\
(c) & 1.66 & & & & & & & & & 0.63 & 96.41 & 1.29 \\
(d) & & & & 92.93 & & & & & 3.69 & & 3.38 & \\
\hline
\end{tabular}

\section{machine depth impact on surface of inclusion}

Table 2 for slab machine by different depth corresponding to the back plate after the statistical results of roll surface inclusions. Results show: a machine depth on the back plate roll surface inclusions had significant effect on the distribution density, when the machine qing depth increased from 0 to $6 \mathrm{~mm}$, surface total inclusion density from 0.627 / was dropped to 0.096 / was.

Table 2 The statistical results of inclusions of plate roll surface

\begin{tabular}{|c|c|c|c|c|}
\hline \multirow{2}{*}{ Type } & \multirow{2}{*}{ Time } & \multicolumn{3}{|c|}{ No. $/ \mathrm{mm}^{2}$} \\
\hline & & $0 \ll \mathrm{D} \ll 5$ & $5<\mathrm{D} \ll 10$ & D) 10 \\
\hline \multirow{2}{*}{$\mathrm{Al}_{2} \mathrm{O}_{3}$} & 0 & 0.307 & 0.154 & 0 \\
\hline & 2 & 0.06 & 0 & 0 \\
\hline \multirow{2}{*}{$\begin{array}{c}\mathrm{Al}_{2} \mathrm{O}_{3}+\mathrm{Ti} \\
\mathrm{O}_{\mathrm{X}}\end{array}$} & 0 & 0.06 & 0.007 & 0 \\
\hline & 2 & 0.03 & 0 & 0 \\
\hline \multirow{2}{*}{$\operatorname{TiN}_{\mathrm{x}}$} & 0 & 0.092 & 0 & 0 \\
\hline & 2 & 0.006 & 0 & 0 \\
\hline \multirow{2}{*}{ others } & 0 & 0.007 & 0 & 0 \\
\hline & 2 & 0 & 0 & 0 \\
\hline
\end{tabular}

\section{Conclusion}

1) by means of rolled automobile plate coating film produced after experimental analysis of the cause of pitting, $\mathrm{Si}, \mathrm{Ca}, \mathrm{Al}, \mathrm{S}, \mathrm{Ti}$ elements such as the corrosion resistant properties of the phosphating film.

2) the microstructure and composition analysis, the author found out that phosphating film defect of $\mathrm{Si}, \mathrm{Ca}, \mathrm{Al}, \mathrm{S}$, Ti elements such as pitting and paint film of elements found in correspondence, in consequence, as a result of $\mathrm{Si}, \mathrm{Ca}, \mathrm{Al}, \mathrm{S}$, Ti elements such as the existence of the affected the normal growth of phosphate film, flawed, prone to become corrosion, pitting behaviors.

3 ) field by controlling the casting machine depth, when the machine qing depth of $6 \mathrm{~mm}$, which can effectively improve the manufacture surface state, reduce the number of substrate surface inclusions, can make the surface inclusion density fell to very low, so as to inhibit the action of the passivation film pitting.

\section{References}

[1] Xu Guanqing Lin Shengrong. Car protective surface treatment technology development [J]. Journal of plating and finishing, 2007, 29 (4) : p. 6. 
[2] li-ming feng, yu-chao niu, Zhang Dianping. Coating process and equipment [M]. Beijing: chemical industry press, 2007:

[3] ShiXiangQin Liu Xionghua, big eka cesium, the influence factors of phosphating film on the surface of steel corrosion resistance [J]. Journal of Shanghai metals, 2000, 22 (3) : p. 5. 